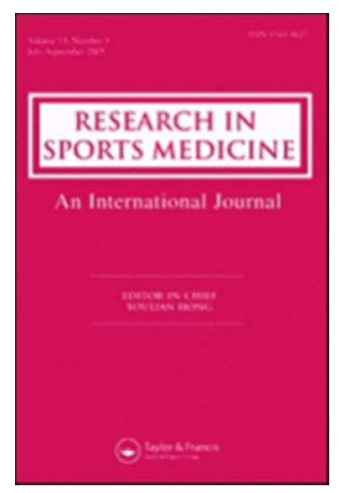

\title{
In-vivo measurement of tri-axial loading at the head during the rugby tackle
}

\begin{tabular}{|r|l|}
\hline Journal: & Research in Sports Medicine \\
\hline Manuscript ID & GSPM-2017-0002.R2 \\
\hline Manuscript Type: & Original Research \\
\hline Keywords: & rugby, accelerometry, head injuries, tackles \\
\hline \multicolumn{2}{|l}{} \\
\hline
\end{tabular}

SCHOLARONE $^{\text {m }}$

Manuscripts 


\section{In-vivo measurement of tri-axial loading at the head during the rugby tackle}

2

\section{Abstract.}

4 To investigate the anatomical distribution of linear and rotational forces during the tackle

5 scenario, male rugby players performed a total of 48 trials, as ball carrier or tackler.

6 Participants wore headgear accommodating three Global Positioning System units

7 measuring uni-axial acceleration at the occipital region (OR), left tempero-parietal (LT-

8 PR) and right tempero-parietal region (RT-PR). An additional unit was located at the

9 cervico-thoracic spinal region (CSR) in a custom vest. There was a significant main effect

10 for tackle condition $(P<0.001)$, with the tackler exposed to significantly greater load than

11 the ball carrier, supporting epidemiological observations. A repeated measures General

12 Linear Model also revealed a significant $(P<0.001)$ main effect for unit location upon 3D

13 load, with significantly higher load at the CSR (1.63 \pm 0.54 a.u $)$ and OR (1.67 \pm 0.94 a.u)

14 units when compared to the LT-PR $(1.23 \pm 0.39$ a.u $)$ and RT-PR $(1.21 \pm 0.44$ a.u $)$ units. The

15 anatomical specificity in loading supports epidemiological observations and provides an 16 insight into potential concussion aetiology.

\section{INTRODUCTION}

19 The incidence of head injuries and concussions in rugby ranges from 6.6-14.6 and 4.1-9.1 20 per 1000 game hours respectively (Kemp, Hudson, Brooks, \& Fuller, 2008; Brooks, Fuller, 21 Kemp, \& Reddin, 2005; Fuller, Sheerin, \& Targett, 2013; Gardner, Iverson, Williams, 22 Baker, \& Stanwell, 2014; Tommasone \& Valovich McLeod, 2006). Whilst catastrophic 23 brain injury in rugby is rare (McCrory, Berkovic, \& Cordner, 2000), concussive injury is 
1 frequent, accounting for up to $25 \%$ of all injuries (McIntosh, 2003). The concussive

2 incidence rate equates to a concussion every 6 matches, with 15 concussions recorded 3 during the 2011 rugby World Cup competition (Fuller et al., 2013). Concussion is a 4 complex pathophysiological process resulting from a direct impact to the head, or to 5 another region of the body causing an abrupt acceleration and/or deceleration to the 6 craniocervical complex (Marshall, 2012). Repeated concussions and mild traumatic brain 7 injury (MTBI) can result in chronic traumatic encephalopathy (CTE) (Roberts, Allsop, \& 8 Bruton, 1990; McKee, Cantu, Nowinski, Hedley-Whyte, Gavett, Budson, et al., 2009; 9 Patricios and Kemp, 2014). The development of CTE can have symptoms of deterioration 10 in attention, memory and concentration which can manifest to overt dementia (McKee et 11 al. 2009). In previous research, at least $17 \%$ of repeated concussion or MTBI sufferers 12 developed CTE (Roberts et al., 1990), and 90\% of neuropathologically confirmed cases of 13 CTE were athletes (90\%).

14 The tackle is the most common facet of play in which head injuries occur within rugby, 15 accounting for 56-64\% (Bird, Waller, Marshall, Alsop, Chalmers, \& Gerrard, 1998; 16 Brooks et al., 2005; Kemp et al., 2008). The tackle scenario is unlikely to be linear; 17 Broglio, Schnebel, Sosnoff, Shin, Fend \& Zimmerman (2010) identified the presence of 18 linear and rotational accelerations of the head, with rotational forces contributing to the 19 mechanism of concussion (Thompson \& Hagedorn, 2012). Video analysis of concussive 20 events within Australian Rules Football, Rugby and Rugby league found that although the 21 majority of concussions occurred as a result of a direct impact to the head, concussion also 22 arose as result of a change in relative momentum of the head relative to the trunk 23 (McIntosh, McCrory, \& Comerford, 2000). The potential for concussive injury via the 24 whiplash mechanism is attributed to the large degrees movement of the head relative to the 25 neck (Ommaya \& Hirsch, 1971; Shaw, 2002). 
1 The relative anatomical accelerations and contribution of linear and rotational forces in

2 concussions present an opportunity in the use of tri-axial accelerometry to investigate the

3 mechanism of head injury in the rugby tackle scenario. GPS technology has been utilised

4 previously in rugby to quantify the demands of playing and training (Reid, Cowman,

5 Green, \& Coughlan, 2013; Jones, West, Crewther, Cook, \& Kilduff, 2015; Hartwig,

6 Naughton, \& Searl, 2011) and to quantify the intensity and frequency of collisions (Suarez-

7 Arronez, Arenas, Lopez, Requena, Terrill, \& Mendez-Villanueva, 2014; Cunniffe, Proctor,

8 Barker, \& Davies, 2009; Venter, Opperman, \& Opperman, 2011). The contemporary

9 development of GPS-based micro-technologies has established a greater degree of 10 reliability due to the higher sampling frequencies (Boyd, Ball, \& Aughey, 2011), and

11 research has demonstrated the efficacy of incorporating tri-axial accelerometry in sports 12 such as netball (Cormack, Smith, Mooney, Young, \& O’Brien, 2014), basketball 13 (Montgomery, Pyne, \& Minahan, 2010) and Australian football (Boyd, Ball, \& Aughey, 14 2013). The aim of the present study is to investigate the efficacy of tri-axial accelerometry 15 in identifying risk factors for head injury during the rugby tackle event. To account for the 16 whiplash mechanism associated with the relative movement of anatomical locations, units 17 will be housed within a protective helmet in addition to the most common placement at the 18 cervico-thoracic junction. Multiple sites at the head are considered to account for the 19 linear and rotational forces which contribute to concussion.

21 MATERIALS AND METHOD

\section{Participants}

23 A total of 24 rugby tackle events were analysed to provide a total of 48 trials ( 24 as tackler 24 and 24 as ball carrier). This data set comprised 12 male rugby union players (age $21.3 \pm$ 
12.2 years; weight $88.7 \pm 5.6 \mathrm{~kg}$; height $1.84 \pm 0.06 \mathrm{~m}$ ), recruited from a single semi-

2 professional club. These 12 players represent a relatively homogeneous sample from

3 within the club, and this was deemed beneficial given the potential impact of

4 anthropometric variability on loading and tackle technique. Furthermore, during testing,

5 matched pairs were established based on weight, height and playing position. All

6 participants were made aware of the purposes and risks of the study prior to any data

7 collection. All participants provided written informed consent, were health screened and

8 reported to be injury free for at least six months prior to data collection. Additionally, each

9 player had a minimum of 8 years of competitive rugby experience, and a current training

10 status equivalent to four training sessions (two rugby-specific sessions) and one

11 competitive match per week. Ethical consent was provided at a Departmental level in

12 accord with the spirit of the declaration of Helsinki.

\section{Experimental Design}

14 A tackle scenario involving two participants, a tackler and ball carrier, was created using

15 either the active shoulder or smother tackles based on their prominence in rugby 16 (McIntosh, Savage, McCrory, Frechede, \& Wolfe, 2010). During each tackle, both the ball 17 carrier and tackler wore modified protective headgear designed to accommodate three 18 Catapult MinimaxX S4 GPS units (Catapult Innovations, Victoria, Australia) with an 19 incorporated tri-axial piezoelectric linear accelerometer (Kionix: KXP94) operating at $20100 \mathrm{~Hz}$. The reliability of these accelerometers has been previously established within the 21 literature as acceptable $(\mathrm{CV}=0.91-1.05 \%)$ in dynamic movements (Boyd et al., 2011). 22 Two units were positioned either side of the skull at the left tempero-parietal region (LT$23 \mathrm{PR}$ ) and right tempero-parietal region (RT-PR) and one was positioned to the rear, at the 24 occipital region (OR) of the skull. A fourth unit was fitted in the customary position 
1 between the scapulae at the thoraco-cervical region (CSR) in the elasticised vests provided

2 by the manufacturer.

3 Prior to data collection, participants engaged in a ten minute warm up incorporating

4 dynamic stretches and standing tackle impacts. Participants were also required to perform

5 ten submaximal tackles, progressing from a stationary crouched position to gradually

6 increasing approach lengths up to the pre-determined experimental set-up of $5 \mathrm{~m}$. This

7 progressive exercise was performed to gradually increase the velocity of contact, and to

8 ensure a safe and ecologically valid technique was achieved by both participants. Player

9 pairs were established prior to experimental trials, and all familiarisation trials were 10 completed in these pairs to establish consistency.

11 Within the experimental pair, each participant completed the active shoulder and smother 12 tackle scenarios as both ball carrier and tackler. These four experimental trials were 13 completed in randomised order across the pairs. In the active shoulder tackle, the tackler's 14 shoulder makes the first point of contact with the ball carrier's trunk region, this is 15 followed by a leg drive and forward momentum to bring the ball carrier to the ground. The 16 smother tackle involves the tackler wrapping his arms around the ball carrier and utilising 17 their momentum to bring them to the ground, rotating with them in the process.

18 Each trial allowed the tackler and ball carrier a run-up sequence of $5 \mathrm{~m}$ before the tackle 19 was performed, in which both tackles resulted in the ball carrier being taken to the ground. 20 The absolute and relative speeds of the ball carrier and tackler influence the incidence and 21 severity of injury (Quarrie \& Hopkins, 2008). In the current study the GPS unit placed at 22 the CSR was used to quantify the forward velocity of both players immediately prior to 23 impact. Familiarisation trials were utilised to establish a consistent expression of effort, 24 and to attain a reliable approach speed by both players. Immediately after impact, the 
1 culmination of the tackle event was also standardised. Familiarisation trials identified that

2 the majority of tackle events utilised a two stride effort to take the ball carrier to the

3 ground. As a result, tacklers were instructed to complete the grounding of the ball carrier

4 with a maximum of two strides: typically the first stride being to establish contact with the

5 ball carrier, and the second stride used to drive the ball carrier to the ground and complete

6 the tackle.

\section{Data Analysis}

8 All data was downloaded using Catapult Sprint software (Version 5.1.1, Catapult 9 Innovations, Victoria, Australia). The forward velocity of the ball carrier and tackler 10 immediately prior to impact were $5.6 \pm 0.3 \mathrm{~m} \cdot \mathrm{s}^{-1}$ and $3.8 \pm 0.2 \mathrm{~m} \cdot \mathrm{s}^{-1}$ respectively. During 11 each tackle, each of the four tri-axial accelerometers (CSR, OR, LT-PR and RT-PR) were 12 analysed for anterior-posterior (AP), medio-lateral (ML) and vertical (V) uni-axial 13 PlayerLoad ${ }^{\mathrm{TM}}$. Uni-axial load was calculated using the equation as described by Boyd, 14 Ball, \& Aughey (2013), and defined using the instantaneous rate of change in acceleration: $15 \sqrt{ }\left[\left(\mathrm{a}_{\mathrm{y} 1}-\mathrm{a}_{\mathrm{y}-1}\right)^{2} / 100\right]$. This was done for each of the three discrete uni-axial vectors.

16 The cumulative tri-axial Total PlayerLoad was also calculated, defined as the sum of the 17 three uni-axial vectors (rather than the square root of the sum as described by Boyd, Ball, $18 \&$ Aughey). This summative tri-axial value was subsequently used to calculate the relative 19 contribution of each plane to total load.

\section{Statistical Analysis.}

21 Statistical analysis and the selected analysis parameters were determined $a$ priori. The 22 assumptions associated with a repeated measures general linear model (GLM) were 23 assessed to ensure model adequacy, including the residual normality for each analysis 24 parameter. Mauchly's test of sphericity was supplemented with a Greenhouse Geisser 
1 correction where appropriate. Subsequent inferential analyses were performed using a

2 mixed method two-way (unit location*tackle condition) repeated measure GLM to

3 examine differences in the loading between the tri-axial accelerometer locations (CSR,

4 OR, LT-PR, RT-PR), and tackle condition (ball carrier, tackler). Where significant main

5 effects or interactions were observed, post-hoc pairwise comparisons with a Bonferroni

6 correction factor were applied. To further identify substantive significance associated with

7 main effects and interactions, partial eta squared $\left(\eta^{2}\right)$ values were calculated to estimate

8 effect sizes. All data are presented as mean \pm SD unless otherwise stated.

10 RESULTS

11 There was a significant main effect $\left(P<0.001, \eta^{2}=0.72\right)$ for unit location with significantly 12 higher $(P \leq 0.001) 3 \mathrm{D}$ load at the CSR $(1.63 \pm 0.54$ a.u $)$ and OR $(1.67 \pm 0.94$ a.u $)$ units when 13 compared to the LT-PR (1.23 \pm 0.39 a.u $)$ and RT-PR (1.21 \pm 0.44 a.u) units. Further analysis 14 revealed a significant main effect $\left(P<0.001, \eta^{2}=0.59\right)$ for tackle condition and a significant 15 interaction $\left(P<0.001, \eta^{2}=0.46\right)$ between unit location and tackle condition.

16 The active shoulder tackler exhibited significantly $(\mathrm{p} \leq 0.001)$ greater Load at CSR

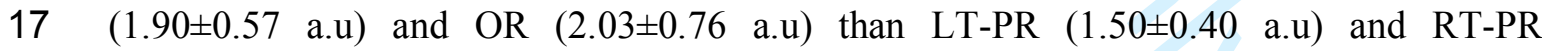
18 (1.49 \pm 0.43 a.u) units. The ball carrier also exhibited significantly higher $(P \leq 0.036) 3 \mathrm{D}$

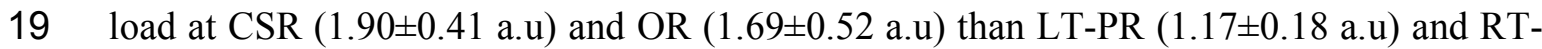
20 PR (1.16 \pm 0.21 a.u).

21 The ball carrier into the smother tackle also exhibited significantly greater $(P \leq 0.001)$ Load 22 at CSR (1.71 \pm 0.33 a.u $)$ and OR $(1.69 \pm 0.45$ a.u $)$ than LT-PR $(1.25 \pm 0.19$ a.u $)$ and RT-PR 23 (1.25 \pm 0.20 a.u). In contrast, the smother tackler exhibited significantly greater $(P \leq 0.013)$ 
1 Load at OR (1.28 \pm 0.15 a.u $)$ than CSR (1.02 \pm 0.39 a.u), LT-PR $(0.99 \pm 0.23$ a.u $)$ and RT-PR

$2(0.95 \pm 0.27$ a.u $)$ units. The influence of tackle condition and unit placement is summarised 3 in Figure 1.

4

7 Table 1 summarises the influence of unit location and tackle condition on the uni-axial 8 Load. There was a significant main effect for unit location in each of the Anterio-Posterior $9 \quad\left(P=0.031, \eta^{2}=0.23\right)$, Medio-Lateral $\left(P<0.001, \eta^{2}=0.87\right)$ and Vertical $\left(P<0.001, \eta^{2}=0.66\right)$ 10 planes. There was also a significant main effect for tackle condition (Anterio-Posterior: $11 P<0.001, \eta^{2}=0.52$; Medio-Lateral: $P<0.001, \eta^{2}=0.55$; Vertical: $P<0.001, \eta^{2}=0.72$ ) and a 12 significant interaction effect between unit location and tackle condition in each plane 13 (Anterio-Posterior: $P<0.001, \quad \eta^{2}=0.44$; Medio-Lateral: $P<0.001, \quad \eta^{2}=0.48$; Vertical: $\left.14 P<0.001, \eta^{2}=0.26\right)$.

15 Post-hoc analysis revealed that Anterio-Posterior loading was significantly higher for the 16 ball carrier at the CSR when compared to the LT-PR and RT-PR in the active shoulder $17(P \leq 0.033)$ and smother tackles $(P \leq 0.037)$. Conversely, AP loading at CSR was 18 significantly less for the tackler during the smother tackle than at either parietal regions $19(P \leq 0.039)$.

20 Medio-Lateral loading was significantly higher at the CSR and OR than LT-PR and RT-PR 21 in all tackle conditions $(P \leq 0.001)$. For the tackler, loading at OR was significantly greater 22 than at $\mathrm{CSR}$ in both conditions (AS: $P=0.009$ : $\mathrm{S}: P=0.017$ ). For the ball carrier, the active 23 shoulder tackle elicited significantly greater ML loading at CSR than OR $(P=0.003)$. 
1 Vertical loading was significantly higher at the CSR and OR than the LT-PR and RT-PR

2 regions in the AS-T $(P \leq 0.018)$, AS-BC $(P \leq 0.002)$, and S-BC $(P \leq 0.045)$ tackle conditions.

3 In the S-T condition, OR loading was significantly greater than at all other locations

$4(P \leq 0.026)$, and LT-PR was significantly higher than RT-PR $(P=0.032)$.

5

6

7

8 AP Load was significantly greater at the CSR than all other sites for the ball carrier in each 9 condition. However the smother tackler exhibited significantly less Load at CSR than all 10 11
** Insert Table 1 near here ** other locations, whilst the active shoulder tackler exhibited no difference between unit locations.

ML Load was significantly greater at CSR and OR than at LT-PR and RT-PR in all tackle conditions, however there was a distinction between ball carrier and tackler. ML Load at CSR was significantly greater than OR for the tackler, but for the ball carrier Load at OR was significantly greater than CSR.

Vertical Load was also significantly greater at CSR and OR than LT-PR and RT-PR for the ball carrier in both conditions, and for the active shoulder tackler. However, for the smother tackler V Load was significantly greater at OR than all other sites, with a symmetry differential evident in LT-PR loading being significantly greater than RT-PR.

The relative contribution of each uni-axial vector to Total Load is summarised in Figure 2. There was a significant $(P<0.001)$ main effect for unit location in each axis. In the ML plane $\left(\eta^{2}=0.96\right)$ the $\%$ contribution was significantly greater at the CSR and OR than the parietal regions. There was a compensatory greater increase in $\%$ contribution in the AP 
$1 \quad\left(\eta^{2}=0.82\right)$ and $\mathrm{V}\left(\eta^{2}=0.49\right)$ planes at LT-PR and RT-PR than at CSR and OR. In the AP 2 plane, the $\%$ contribution was significantly higher $(P=0.032)$ at CSR than OR.

3

4

5

6 In relative axial loading, there was a significant main effect for tackle condition in the ML

$7 \quad\left(P<0.001, \eta^{2}=0.76\right)$ and $\mathrm{V}\left(P<0.001, \eta^{2}=0.81\right)$ planes, but not in the AP plane $(P=0.272$,

$8 \eta^{2}=0.11$ ). There was a significant interaction effect between unit location and tackle

9 condition in the $\%$ contribution of all planes (ML: $P<0.001, \eta^{2}=0.31$; AP: $P<0.001$,

$\left.10 \eta^{2}=0.33 ; \mathrm{V}: P=0.001, \eta^{2}=0.24\right)$. This data is summarised in Table 2.

11 The tackler exhibited significantly greater $(P \leq 0.001)$ AP \% loading at the PR locations

12 than CSR and OR. In the active shoulder tackle, relative AP loading was significantly

13 higher $(P=0.002)$ at CSR than OR. The ball carrier in the active shoulder tackle exhibited

14 significantly greater AP \% loading at RT-PR than at CSR and OR $(P \leq 0.017)$, whereas this

15 relative loading was significantly greater $(P \leq 0.020)$ at LT-PR in the smother tackle.

16 The greater AP\% contribution in the PR sites was also evident in the V plane. For the

17 tackler, V \% at LT-PR was significantly greater $(P \leq 0.001)$ than OR in the active shoulder

18 tackle, and significantly greater $(P \leq 0.001)$ than CSR in the smother tackle. For the ball

19 carrier, relative V loading was significantly higher at RT-PR than CSR and OR in the

20 active shoulder $(P=0.026)$ and smother $(P \leq 0.001)$ tackle. In the active shoulder tackle,

21 relative loading at OR was significantly greater $(P \leq 0.001)$ than at CSR.

22 Conversely, the ML \% contribution to total Load was significantly lower in the PR

23 locations in all tackle conditions. In the active shoulder tackle, the relative loading was 
1 significantly higher at OR than CSR $(P<0.001)$ for the tackler, but significantly higher at

2 CSR than OR for the ball carrier $(P=0.017)$. For the ball carrier, LT-PR exhibited higher

3 relative loading than RT-PR $(P=0.037)$. In the smother tackle, relative ML loading at CSR

4 and OR were significantly greater $(P<0.001)$ than at PR locations for tackler and ball

5 carrier. The smother tackler exhibited significantly greater $(P=0.019)$ loading at RT-PR

6 than LT-PR.

7

\section{DISCUSSION}

11 Placing wearable technology in helmets has informed understanding of the biomechanics 12 of concussion (Broglio et al., 2010; Broglio, Eckner, Martini, Sosnoff, Kutcher, \&

13 Randolph, 2011). The aim of the present study was to assess the efficacy of incorporating

14 multiple tri-axial accelerometers within protective headgear in identifying risk factors for 15 injury. The neoprene headgear used has limited capacity to attenuate impact energy 16 (McIntosh, McCrory, Finch, Best, Chalmers, \& Wolfe, 2009; McIntosh et al., 2000) and

17 thus negates the influence of the headgear itself on measures of accelerometry. The 18 product used in this study was a commercially available scrum cap, carrying the IRB 19 approval logo, and meeting the requirement that no part of the headgear is thicker than $2010 \mathrm{~mm}$ when uncompressed and with a density of no more than $45 \mathrm{~kg} / \mathrm{m}^{3}$. Critical 21 discussion of the load magnitudes is limited by a lack of similar research, but the 22 implications of unit placement have been considered previously (Barrett, Midgley, 23 \&Lovell, 2014 
1 The tempero-parietal region was identified by McIntosh et al. (2000) as the most frequent

2 site of concussive injuries in rugby, informing placement in this study. Total load was

3 significantly lower in the peripheral tempero-parietal regions when compared to the central

4 occipital and cervico-thoracic regions. The greater magnitude of loading in the central

5 regions might be attributed to the initial point of impact and the prevalence of linear (rather

6 than rotational) forces in these tackle scenarios. This is indicative of the primary influence

7 of linear forces where both players are moving forward. The front on tackle has greatest

8 propensity to cause concussion (Kemp et al., 2008) due to the greater presence of linear

9 forces, which are key contributors to concussive injury (Broglio et al., 2010; Pellman,

10 Viano, Tucker, Casson, \& Waeckerle, 2003).

11 The loading pattern supports the epidemiological literature indicating the tackler is at the 12 greatest risk of head injury (Kemp et al., 2008; Bird et al., 1998). The greater loading in 13 central regions was observed in all conditions, but in the smother tackle the tackler was 14 subjected to a significantly greater load at the OR. This tackle is performed front-on, in an 15 upright position with the initial point of contact being the sternum. Analyses of AP load 16 confirmed greater magnitudes in all units positioned within the headgear relative to the 17 CSR, creating an impulse resulting in the head being set in motion relative to the trunk 18 (Shaw, 2002). This whiplash mechanism contributes to concussion in contact sports 19 (McIntosh et al., 2000).

20 In the active shoulder technique, the tackler is advised to position their head to the side of 21 the ball carrier to reduce the likelihood of a direct head impact. The tackler using this 22 technique was exposed to a greater absolute and relative medio-lateral load at OR. The 23 initiation of rotational forces have been regarded a key risk factor to concussion in contact 24 sport (Broglio et al., 2010, 2011; Guskiewicz, Mihalik, Shankar, Marshall, Crowell, Oliaro, 25 et al., 2007; Broglio, Surma, \& Ashton- Miller, 2010). The relative differences in ML load 
1 between anatomical sites suggest there is propensity for medio-lateral whiplash due to the

2 large freedom of movement of the head. This could increase the propensity of a collision

3 between the brain floating in the cerebrospinal fluid and the stiff walls of the skull, causing

4 a concussion (Shaw, 2002; Wilberger, Ortega, \& Slobounov, 2006). Conversely, the ball

5 carrier into the active shoulder tackle exhibited significantly greater 3D load at the CSR

6 region. The points of contact and transferal of kinetic energy differ between the tackler and

7 ball carrier (Quarrie \& Hopkins, 2008; Fuller, Brooks, Cancea, Hall, \& Kemp, 2007b).

8 There was lower (absolute and relative) anterio-posterior load at the CSR than the OR in

9 all tackle conditions, with a compensatory increase in medio-lateral and vertical loading

10 contributions. Previous research investigating the biomechanics of head impacts has

11 emphasised the importance of the role of both linear and rotational accelerations in

12 concussive injury (Broglio et al., 2010, 2011) The proposed rotational component induced

13 by the presence of lateral forces, has been suggested to have great propensity to cause

14 concussion due to the increased strain on brain stem integrity (Guskiewicz et al., 2007;

15 Broglio, Surma, \& Ashton-Miller, 2010) which is derived from the anatomical linear

16 alignment of the brain stem itself (Ommaya \& Gennarelli, 1974).

17 The sensitivity of unit placement and the tri-axial nature of loading patterns suggests 18 potential in head injury screening. For example, the significant difference in loading 19 between the occipital skull and cervico-thoracic junction might inform analysis and 20 identification of the whiplash mechanism. Up to $90 \%$ of sport related concussions occur 21 without loss of consciousness (Cantu, 1996) and there is no "gold standard" for diagnosing 22 concussion. Repeated concussions are usually more severe (Saffary, Chin, \& Cantu, 2012) 23 and the propensity of suffering a second concussion is increased by up to three-fold 24 (Guskiewicz, Weaver, Padua, \& Garrett, 2000). The efficacy of this tool is therefore 25 encouraging as it could be incorporated alongside other assessment tools to improve 
1 diagnosis of concussive injury. The present study has demonstrated the efficacy of

2 positioning micro-technology upon the head, which could be further utilised to determine

3 whether a player has experienced too great a load upon the head in a game/ head injury

4 incident to allow them to return to training or play too soon. This could protect players

5 from repeated concussive injuries, decreasing the propensity of insidious long- term

6 neuropathological conditions (McKee et al., 2009; Patricios \& Kemp, 2014). In the

7 present study such a threshold would relate to the magnitude of acceleration, but recently

8 the potential of exposure thresholds based on frequency of heading in soccer has been

9 considered (Catenaccio, Caccese, Wakschlag, Fleysher, Kim, Kim, et al., 2016). The

10 authors describe HeadCount, a 2 week recall questionnaire that was used to quantify the

11 product of number of games and average number of headers per game. Catenaccio et al.

12 reported this inexpensive and logistically convenient instrument to be a valid means for

13 monitoring frequency of exposure, and advocated applications in other sport. A

14 combination of magnitude and frequency monitoring should therefore be considered.

15 Concerns of injury in youth sport being detrimental to physical development (Emery, 16 2010) and epidemiological studies still denoting high incidence and severity of head 17 injuries and concussion in youth rugby (Bleakley, Tully, \& O’Connor, 2011; Haseler, 18 Carmont, \& England, 2010; McIntosh et al., 2009) supports the use of this tool in youth 19 rugby. Future research quantifying the biomechanics of concussive injuries could be 20 correlated alongside other management protocols, such as investigation into clinical 21 symptomology, neuropsychological function and postural stability, to establish this tool as 22 another potential measure to monitor the concussive risk in collision sports. Rule changes 23 present an alternate opportunity to influence injury risk. Caccese, Lamond, Buckley, \& 24 Kaminski (2016) recently advocated rule modifications for young soccer players to reduce 25 heading in soccer in technical scenarios where ball velocity is greatest, specifically from 
1

2

3

4

5

6

7

8

9

1 goal kicks and punts. The authors utilised a triaxial accelerometer and gyro located at the

2 back of the head around the nuchal line to quantify peak linear and rotational head 3 accelerations during match-play. Interestingly, about a third of impacts which exceeded

4 the predetermined $10 \mathrm{~g}$ threshold for analysis were non-head impact events, with the

5 authors identifying sliding to the ground and contact with another player as scenarios

6 which also resulted in high head accelerations. Caccese et al. (2016) in advocating a

7 restriction on high-velocity heading scenarios cite previous rule changes in sport designed

8 to protect the athlete, including Yang \& Baugh (2016) in soccer who placed age-specific

9 restrictions on heading exposure, and modified kick-off rules (Ruestow, Duke, Finley, \& 10 Pierce, 2015) and full-contact practice restrictions (Reynolds, Patrie, Henry, Goodkin,

11 Broshek, Wintermark, et al., 2016) in football.

12 Through comparison of the relative raw planar acceleration between units positioned on 13 the head and CSR, it may be possible to quantify magnitudes of acceleration/deceleration 14 of the head relative to the scapulae that initiate concussion via potential whiplash 15 mechanisms. Figure 3 depicts an example of the relative difference in CSR and OR 16 anterio-posterior acceleration during a tackle scenario. If these analyses were utilised in 17 future ecological incidents of diagnosed head injury through systematic use of the 18 technology, potential quantification and identification of the aetiology of concussion is 19 possible. This could develop normative acceleration/deceleration thresholds to assist 20 diagnostics of concussive injuries. 
1 It must be acknowledged that the data presented in the current study cannot be generalised

2 beyond this population and choice of tackle scenarios. In trying to establish a consistent

3 experimental paradigm there are inevitably compensations in ecological validity. There

4 are a number of factors which influence the tackle event, and ultimately the injury risk.

5 Quarrie \& Hopkins (2008) cited running speed as an aetiological risk factor, but qualified

6 speed with descriptors such as jog, run, or sprint. In the current study a speed of $\sim 20 \mathrm{~km} / \mathrm{hr}$

7 was attained prior to contact by the ball carrier, with a relatively lower speed attained by

8 the tackler. It is difficult to directly compare these values with the literature, but they will

9 inevitably influence loading magnitudes. An extension of the experimental paradigm to

10 include a more diverse range of tackle techniques, impact speeds, and also mis-matched

11 pairs of subjects would further enhance ecological validity. In ensuring a consistent tackle

12 event, the random and unpredictable nature of this scenario is negated. The present study

13 did not consider the influence of any evasive movements for example, and this might

14 influence the velocity and loading at impact. Furthermore, the data presented more

15 accurately represents the acceleration of the protective headgear rather than the head.

16 There is potential for relative movement of the head within the headgear which is not

17 accounted for, and this must be acknowledged in interpretation. The consideration of

18 protective equipment beyond that used in the present study would also have merit.

19 In conclusion, unit location and tackle condition had a significant effect on the magnitude

20 and tri-axial nature of loading. The relative acceleration of different anatomical regions

21 has potential in quantifying the whiplash mechanism commonly cited in concussive events.

22 The greater load elicited in centrally located CSR and OR units suggests that linear forces

23 are most prominent in front on tackles, supporting epidemiological observations. The

24 present study has also highlighted evident loading dissimilarities between players in

25 alternative roles and tackle techniques, which supports epidemiological observations, 
1 denoting the tackler is of greatest risk of head injury. Variations in elicited load between

2 altering unit placements, within different facets of play has provided an insight into the

3 potential aetiology of head injuries sustained within specific areas of the game. This could

4 provide a basis for the instigation of further passive interventions to increase the safety of

5 the game. Considering the findings of the present study and the proposed practical

6 applications, there is evident potential for further applications in certain wearable

7 technologies for the assessment of concussion risk and/or management in rugby and other

8 football codes.

9

10

11 No potential conflict of interest was reported by the authors.

\section{REFERENCES.}

13 1. Barrett, S., Midgley, A., \& Lovell, R. (2014). PlayerLoad ${ }^{\mathrm{TM}}$ : Reliability, convergent

14 validity, and influence of unit position during 55 treadmill running. International

15 Journal of Sports Physiology and Performance, 9(6), 945-952.

16 2. Bird, Y. N., Waller, A. E., Marshall, S. W., Alsop, J. C., Chalmers, D. J., \& Gerrard,

17 D. F. (1998). The New Zealand rugby injury and performance project V:

18 Epidemiology of a season of rugby injury. British Journal of Sports Medicine. 32, $19 \quad 319-325$.

20 3. Bleakley, C., Tully, M., \& O'Connor, S. (2011). Epidemiology of adolescent rugby 21 injuries: A systematic review. Journal of Athletic Training. 46(5), 555-565. 
1 4. Boyd, L. J., Ball, K., \& Aughey, R. J. (2011). The reliability of minimaxX

2 accelerometers for measuring physical activity in Australian football. International

3 Journal of Sports Physiology and Performance, 6, 311-321.

4 5. Boyd, L. J., Ball, K., \& Aughey, R. J. (2013). Quantifying external load in Australian

5 football matches and training using accelerometers. International Journal of Sports

$6 \quad$ Physiology and Performance, 8, 44-51.

7 6. Broglio, S. P., Eckner, J. T., Martini, D., Sosnoff, J. J., Kutcher, J. S., \& RandolpH, C.

8 (2011). Cumulative head impact burden in high school football. Journal of

$9 \quad$ Neurotrauma, 28, 2069-2078.

10 7. Broglio, S. P., Schnebel, B., Sosnoff, J. J., Shin, S., Fend, X., He, X., \& Zimmerman,

11 J. (2010). Biomechanical properties of concussions in high school football. Medicine

12 and Science in Sports and Exercise, 42, 2064-2071.

13 8. Broglio, S. P., Surma, T., \& Ashton- Miller, J. A. (2010). High school and collegiate

14 football athlete concussions: A biomechanical review. Annals of Biomedical

$15 \quad$ Engineering, 40(1), 37-46.

16 9. Brooks, J. H. M., Fuller, C. W., Kemp, S. P. T., \& Reddin, D. B. (2005).

17 Epidemiology of injuries in English professional rugby union: part 1 match injuries.

18 British Journal of Sports Medicine, 39, 757-766.

19 10. Caccese, J. B., Lamond, L. C., Buckley, T. A., \& Kaminski, T. W. (2016). Reducing

20 purposeful headers from goal kicks and punts may reduce cumulative exposure to head

21 acceleration. Research in Sports Medicine, 24(4), 407-415.

22 11. Cantu, R. C. (1996). Head injuries in sport. British Journal of Sports Medicine, 30, $23 \quad 289-296$.

24 12. Catenaccio, E., Caccese, J., Wakschlag, N., Fleysher, R., Kim, N., Kim, M., Buckley,

25 T. A., Stewart, W. F., Lipton, R. B., Kamisnki, T., \& Lipton, L. (2016). Validation 

and calibration of HeadCount, a self-report measure for quantifying heading exposure in soccer players. Research in Sports Medicine, 24(4), 416-425.

13. Cormack, S. J., Smith, R. L., Mooney, M. M., Young, W. B., \& O’Brien, B. J. (2014). Accelerometer load as a measure of activity profile in different standards of netball match play. International Journal of Sports Physiology and Performance, 9(2), 283291.

14. Cunniffe, B., Proctor. W., Barker, J. S. \& Davies, B. (2009). An evaluation of the physiological demands of elite rugby union using global positioning system tracking system. Journal of Strength and Conditioning Research, 23(4), 1195-1203.

15. Emery, C. A. (2010). Injury prevention in paediatric sport-related injuries: A scientific approach. British Journal of Sports Medicine, 44, 64-69.

16. Fuller, C. W., Brooks, J. H., Cancea, R. J., Hall, J., \& Kemp, S. P. (2007). Contact events in rugby union and their propensity to cause injury. British Journal of Sports Medicine, 41(12), 862-867.

17. Fuller, C. W., Sheerin, K., \& Targett, S. (2013). Rugby World Cup 2011: International Rugby Board injury surveillance study. British Journal of Sports Medicine, 47, 11841191.

18. Gardner, A., Iverson, G., Williams, W., Baker, S., \& Stanwell, P. (2014). A systematic review and meta-analysis of concussion in rugby union. Sports Medicine, 44(12), 1717-1731.

19. Guskiewicz, K. M., Weaver, N. L., Padua, D. A., \& Garrett, W .E. (2000). Epidemiology of concussion in collegiate and high school football players. American Journal of Sports Medicine, 28, 643-650.

20. Guskiewicz, K. M., Mihalik, J. P., Shankar, V., Marshall, S. W., Crowell, D. H., Oliaro, S. M., Ciocca, M. F., \& Hooker, D. N. (2007). Measurement of head impacts 
1 in collegiate football players: relationship between head impact biomechanics and

2 acute clinical outcome after concussion. Neurosurgery, 61(6), 1244-1252.

3 21. Hartwig, T. B., Naughton, G., \& Searl, J. (2011). Motion analyses of adolescent rugby

4 union players: A comparison of training and game demands. Journal of Strength and

$5 \quad$ Conditioning Research, 25 (4), 966-972.

6 22. Haseler, C. M., Carmont, M. R., \& England, M. (2010). The epidemiology of injuries

7 in English youth community rugby union. British Journal of Sports Medicine, 44,

8 1093-1099.

9 23. Jones, M. R., West, D. J., Crewther, B. T., Cook, C. J., \& Kilduff, L. P. (2015).

10 Quantifying positional and temporal movement patterns in professional rugby union

11 using global positioning system. European Journal of Sport Science, 12, 1-9.

12 24. Kemp, S. P. T., Hudson, Z., Brooks, J. H. M., \& Fuller, C. W. (2008). The

13 epidemiology of head injuries in English professional rugby union. Clinical Journal of $14 \quad$ Sports Medicine, 18(3), 227-234.

15 25. Marshall, C. M. (2012). Sports-related concussion: A narrative review of the literature.

16 Journal of the Canadian Chiropractic Association, 56 (4), 299-310.

17 26. McCrory, P. R., Berkovic, S. F., \& Cordner, S. M. (2000). Deaths due to brain injury

18 among footballers in Victoria, 1968-1999. The Medical Journal of Australia, 172 (5), $19 \quad 217-219$.

20 27. McIntosh, A. S. (2003). Helmets and head protection for the athlete as a means to 21 prevent injury. Official Journal of the International Federation of Sports Medicine, 4 22 (1), 1-9.

23 28. McIntosh, A. S., McCrory, P., \& Comerford, J. (2000). The dynamics of concussive 24 head impacts in rugby and Australian rules football. Medicine and Science in Sports 25 and Exercise, 32 (12), 1980-1984. 
1 29. McIntosh, A. S., McCrory, P., Finch, C. F., Best, J. P., Chalmers, D. J., \& Wolfe, R.

2 (2009). Does padded headgear prevent head injury in rugby union football? Medicine $3 \quad$ and Science in Sports and Exercise, 41 (2), 306-313.

4 30. McIntosh, A. S., Savage, T. N., McCrory, P., Frechede, B. O., \& Wolfe, R. (2010).

5 Tackle characteristics and injury in a cross section of rugby union football. Medicine

$6 \quad$ and Science in Sports and Exercise, 42 (5), 977-984.

7 31. McKee, A. C., Cantu, R. C., Nowinski, C. J., Hedley-Whyte, E. T., Gavett, B. E.,

8 Budson, A. E, Santini, V. E., Lee, H., Kubilus, C. A., \& Stern, R. A. (2009). Chronic

9 traumatic encephalopathy in athletes: Progressive tauopathy following repetitive head 10 injury. Journal of Neuropathology and Experimental Neurology, 68(7), 709-735.

11 32. Montgomery, P. G., Pyne, D., \& Minahan, C. L. (2010). The physical and

12 physiological demands of basketball training and competition. International Journal of 13 Sports Physiology and Performance, 5, 75-86.

14 33. Ommaya, A. K. \& Hirsch, A. E. (1971). Tolerances for cerebral concussion from head 15 impact and whiplash in primates. Journal of Biomechanics, 4, 13-21.

16 34. Ommaya, A. K., \& Gennarelli, T. A. (1974). Cerebral concussion and traumatic unconsciousness: Correlation of experimental and clinical observations on blunt head injuries. Brain, 97, 633-654.

35. Patricios, J. S., \& Kemp, S. P. T. (2014). Chronic traumatic encephalopathy: Rugby's call for clarity, data and leadership in the concussion debate. British Journal of Sports Medicine, 48 (2), 76-79.

36. Pellman, E. J., Viano, D. C., Tucker, A. M., Casson, I. R., \& Waeckerle, J. F. (2003). Concussion in professional football: Reconstruction of game impacts and injuries.

$24 \quad$ Neurosurgery, 35 (4), 799- 814. 
1 37. Quarrie, K. L., \& Hopkins, W. G. (2008). Tackle injuries in professional rugby union. 2 American Journal of Sports Medicine, 36(9), 1705-1716.

3 38. Reid, L. C., Cowman, J. R., Green, B. S., \& Coughlan, G.F. (2013). Return to play in

6 39. Reynolds, B. B., Patrie, J., Henry, E. J., Goodkin, H.P., Broshek, D. K., Wintermark,

$7 \quad$ M., \& Druzgal, T. J. (2016). Practice type effects on head impact in collegiate

8 football. Journal of Neurosurgery, 124(2), 501-510.

9 40. Roberts, G. W., Allsop, D., \& Bruton C. (1990). The occult aftermath of boxing. Journal of Neurology Neurosurgery and Psychiatry, 53, 373-378.

41. Ruestow, P. S., Duke, T. J., Finley, B. L., \& Pierce, J.S. (2015). Effects of the NFL's amendments to the free kick rule on injuries during the 2010 and 2011 seasons. Journal of Occupational and Environmental Hygiene, 12(12), 875-882.

42. Saffary, R., Chin, L. S., \& Cantu, R. C. (2012). From concussion to chronic traumatic encephalopathy: A review. Journal of Clinical Sport Psychology, 6, 351-362.

43. Shaw, N. (2002). The neurophysiology of concussion. Progress in Neurobiology, 67(4), 281-344.

44. Suarez-Arrones, L., Arenas, C., López, G., Requena, B., Terrill, O., \& MendezVillanueva, A. (2014). Positional differences in match running performance and physical collisions in men rugby sevens. International Journal of Sports Physiology and Performance, 9, 316-323.

45. Thompson, J. W. G. \& Hagedorn, D. (2012). Multimodal analysis: New approaches to the concussion conundrum. Journal of Clinical Sport Psychology, 6, 22-46.

24 46. Tommasone, B. A. \& Valovich Mcleod, T. C. (2006). Contact sport concussion incidence. Journal of Athletic Training, 41(4), 470-472. 
1

2

3

4

5

6

7

8

9

10

1 47. Venter, R., Opperman, E., \& Opperman, S. (2011). The use of global positioning

10 system (GPS) tracking devices to access movement demands and impacts in under-19 rugby union match play. African Journal of Physical, Health Education and Recreation and Dance, 17 (1), 1-8.

48. Wilberger, J., Ortega, J., \& Slobounov, S. (2006). Foundations of Sport-Related Brain Injuries. USA: Springer US.

49. Yang, Y. T., \& Baugh, C. M. (2016). US Youth Soccer concussion policy: Heading in the right direction. JAMA Pediatrics, 170(5), 413-414.

\section{LEGENDS TO TABLES \& FIGURES}

Table 1. The influence of tackle condition and unit location on uni-axial Load.

Table 2. The relative uni-axial contributions to Load.

Figure 1. The influence of tackle condition and unit location on Total PlayerLoad.

Figure 2. The influence of unit location on the relative uni-axial contributions to Load.

Figure 3. The relative acceleration of CSR and OR to quantify the whiplash mechanism. 


\begin{tabular}{|c|c|c|c|c|}
\hline Tackle & Unit & \multicolumn{3}{|c|}{ Uni-Axial Player Load (a.u) } \\
\hline Condition & Location & AP & ML & V \\
\hline \multirow{4}{*}{ AS-T } & CSR & $0.56 \pm 0.19$ & $0.62 \pm 0.21$ & $0.71 \pm 0.18$ \\
\hline & OR & $0.53 \pm 0.22$ & $0.76 \pm 0.30$ * & $0.75 \pm 0.25$ \\
\hline & LT-PR & $0.54 \pm 0.14$ & $0.37 \pm 0.11^{* \wedge}$ & $0.60 \pm 0.17 * \Lambda$ \\
\hline & RT-PR & $0.53 \pm 0.18$ & $0.38 \pm 0.11^{* \wedge}$ & $0.58 \pm 0.16 * \wedge$ \\
\hline \multirow{4}{*}{ AS-BC } & CSR & $0.59 \pm 0.16$ & $0.54 \pm 0.14$ & $0.77 \pm 0.19$ \\
\hline & OR & $0.49 \pm 0.18$ * & $0.42 \pm 0.15$ * & $0.78 \pm 0.20$ \\
\hline & LT-PR & $0.39 \pm 0.06 * \wedge$ & $0.22 \pm 0.06 * \wedge$ & $0.57 \pm 0.10 * \wedge$ \\
\hline & RT-PR & $0.40 \pm 0.07^{* \wedge}$ & $0.20 \pm 0.07^{* \wedge}$ & $0.56 \pm 0.08 * \wedge$ \\
\hline \multirow{4}{*}{ S-T } & CSR & $0.30 \pm 0.06$ & $0.36 \pm 0.07$ & $0.36 \pm 0.03$ \\
\hline & OR & $0.35 \pm 0.11$ & $0.47 \pm 0.16$ * & $0.47 \pm 0.14$ * \\
\hline & LT-PR & $0.37 \pm 0.07$ * & $0.24 \pm 0.08^{* \wedge}$ & $0.39 \pm 0.09^{\wedge}$ \\
\hline & RT-PR & $0.35 \pm 0.09$ * & $0.24 \pm 0.08^{* \wedge}$ & $0.36 \pm 0.11^{\wedge} \$$ \\
\hline \multirow{4}{*}{ S-BC } & CSR & $0.52 \pm 0.11$ & $0.53 \pm 0.12$ & $0.67 \pm 0.14$ \\
\hline & OR & $0.52 \pm 0.16$ & $0.52 \pm 0.17$ & $0.66 \pm 0.16$ \\
\hline & LT-PR & $0.45 \pm 0.06$ * & $0.28 \pm 0.07^{* \wedge}$ & $0.52 \pm 0.10 * \wedge$ \\
\hline & RT-PR & $0.41 \pm 0.08 * \wedge$ & $0.28 \pm 0.08^{* \wedge}$ & $0.56 \pm 0.06 * \wedge$ \\
\hline
\end{tabular}

* denotes significantly different than CSR

^ denotes significantly different than OR

\$ denotes significantly different than LT-PR 


\begin{tabular}{|c|c|c|c|c|}
\hline \multirow{2}{*}{$\begin{array}{c}\text { Tackle } \\
\text { Condition }\end{array}$} & \multirow{2}{*}{$\begin{array}{c}\text { Unit } \\
\text { Location }\end{array}$} & \multicolumn{3}{|c|}{ Uni-Axial Contribution (\%) } \\
\hline & & AP & ML & V \\
\hline \multirow{4}{*}{ AS-T } & CSR & $29.24 \pm 3.09$ & $32.38 \pm 1.90$ & $38.38 \pm 4.38$ \\
\hline & OR & $25.44 \pm 2.35$ * & $37.15 \pm 2.38$ * & $37.41 \pm 2.84$ \\
\hline & LT-PR & $35.70 \pm 3.01^{* \wedge}$ & $24.64 \pm 3.00 * \wedge$ & $39.66 \pm 2.44^{\wedge}$ \\
\hline & RT-PR & $35.44 \pm 3.32 * \wedge$ & $25.28 \pm 2.05 * \wedge$ & $39.29 \pm 4.34$ \\
\hline \multirow{4}{*}{ AS-BC } & CSR & $30.85 \pm 3.71$ & $28.71 \pm 4.41$ & $40.44 \pm 7.02$ \\
\hline & OR & $28.47 \pm 3.02$ & $24.73 \pm 2.15^{*}$ & $46.79 \pm 4.13^{*}$ \\
\hline & LT-PR & $33.47 \pm 3.29^{\wedge}$ & $18.23 \pm 3.29 * \wedge$ & $48.31 \pm 4.86$ * \\
\hline & RT-PR & $34.56 \pm 2.71^{* \wedge}$ & $16.60 \pm 3.39 * \wedge \$$ & $48.85 \pm 2.86^{* \wedge}$ \\
\hline \multirow{4}{*}{ S-T } & CSR & $29.18 \pm 1.91$ & $35.36 \pm 2.60$ & $35.46 \pm 3.51$ \\
\hline & OR & $27.20 \pm 3.81$ & $36.30 \pm 4.10$ & $36.50 \pm 3.74$ \\
\hline & LT-PR & $37.51 \pm 4.65^{* \wedge}$ & $23.61 \pm 3.13 * \wedge$ & $38.88 \pm 3.16$ * \\
\hline & RT-PR & $37.31 \pm 2.83^{* \wedge}$ & $25.28 \pm 2.31 * \wedge \$$ & $37.41 \pm 2.27$ \\
\hline \multirow{4}{*}{ S-BC } & CSR & $30.24 \pm 2.46$ & $30.76 \pm 3.69$ & $39.00 \pm 2.85$ \\
\hline & OR & $30.31 \pm 3.25$ & $30.23 \pm 3.80$ & $39.45 \pm 3.72$ \\
\hline & LT-PR & $36.10 \pm 3.68 * \wedge$ & $22.17 \pm 3.78 * \wedge$ & $41.74 \pm 4.06$ \\
\hline & RT-PR & $32.74 \pm 2.14^{\wedge} \$$ & $21.88 \pm 4.14^{* \wedge}$ & $45.38 \pm 3.95^{* \wedge}$ \\
\hline
\end{tabular}

\footnotetext{
* denotes significantly different than CSR

${ }^{\wedge}$ denotes significantly different than OR

\$ denotes significantly different than LT-PR
} 
Figure 1. The influence of tackle condition and unit location on Total PlayerLoad. $338 \times 190 \mathrm{~mm}(96 \times 96 \mathrm{DPI})$ 


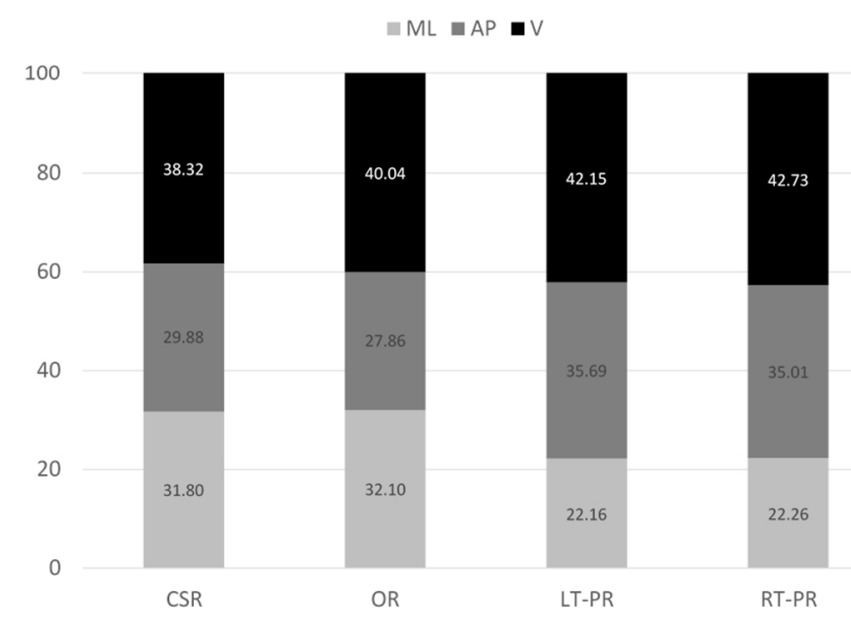

Figure 2. The influence of unit location on the relative uni-axial contributions to Load. $338 \times 190 \mathrm{~mm}(96 \times 96$ DPI $)$ 
Figure 3. The relative acceleration of CSR and OR to quantify the whiplash mechanism. $338 \times 190 \mathrm{~mm}(96 \times 96 \mathrm{DPI})$ 